\title{
Aspergillus-PCR in bronchoalveolar lavage for detection of invasive pulmonary aspergillosis in immunocompromised patients
}

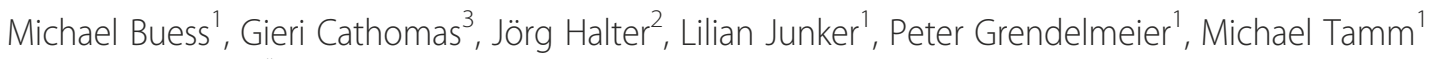
and Daiana Stolz ${ }^{1 *}$

\begin{abstract}
Background: Invasive fungal disease (IFD) is a frequent and serious infectious complication in immunocompromised patients. Culture and cytology in bronchoalveolar lavage (BAL) have a high specificity but low sensitivity for the diagnosis of IFD as assessed by histology. Molecular methods are expected to allow a rapid diagnosis of IFD with a high sensitivity. We evaluated the diagnostic accuracy of conventional nested PCR in the bronchoalveolar fluid to diagnose IFD in severely immunocompromised patients.
\end{abstract}

Methods: Consecutive immunosuppressed patients undergoing bronchoscopy for suspected pulmonary infection in a tertiary care hospital were included. Patients were classified as having "proven", "probable", "possible", and "no" IFD based on definitions of the European Organization for Research and Treatment of Cancer and National Institute of Allergy and Infectious Diseases (EORTC/NIAID) and on clinical grounds. Conventional nested PCR for aspergillus fumigatus, flavus, niger, glaucus, terreus and tomarrii were applied to $2.5 \mathrm{ml}$ bronchoalveolar fluid.

Results: A total of 191 patients were included. Mean age was 51 y, 61\% were male. There were 129 patients with hematological conditions, 26 solid organ transplant recipients, 24 auto-immune disorders, and $12 \mathrm{HIV}$. According to the EORTC/NIAID classification, there were 53 patients with potential IFD: 3 (2\%) had proven, 8 (4\%) probable, $42(22 \%)$ possible and 138 (72\%) no IFD. A total of 111 (58\%) of the patients - 10 (90.9\%) proven or probable IFD, 32 (76.2\%) possible IFD and 69 (50\%) "no" IFD) were on anti-fungal therapy at the time of bronchoscopy. Conventional nested PCR for Aspergillus was positive in 55 cases (28.8\%). According to these results, sensitivity, specificity, PPV and NPV for "proven" IFD was 0\%, 71\%, 0\%, 98\%, respectively and "probable" IFD was 36\%, 72\%, 7\%, 95\%, respectively. In 53 (28\%) cases there was a strong clinical suspicion of IFD in the chest-x-ray and/or chest-CT irrespective of the EORTC/NIAID classification. However, from those, only 15 (28\%) had a positive conventional nested PCR.

Conclusion: In our experience, conventional nested Aspergillus PCR in the BAL seems to be of limited usefulness for detection of invasive fungal disease in immunocompromised patients due to the limited sensitivity and specificity of the method.

Keywords: Invasive aspergillosis, Lung infection, Diagnosis, Bronchoscopy, Conventional nested PCR

\footnotetext{
*Correspondence: dstolz@uhbs.ch

${ }^{1}$ Clinic of Pulmonary Medicine and Respiratory Cell Research, University

Hospital Basel, Basel, Switzerland

Full list of author information is available at the end of the article
} 


\section{Background}

Invasive fungal disease (IFD) is a frequent and serious infectious complication in immunocompromised patients. Despite the introduction of voriconazole and other new antifungal agents the mortality remains as high as 30\% [1]. For instance, the treatment of invasive aspergillosis with intravenous antifungal therapy produced median hospital costs of $\$ 52803$ between 2000 and 2006 in the US, although the mortality stayed up to $36.7 \%$ [2].

Typical features of IFD on CT scan include the halo sign or cavities. However, in many cases, there are only unspecific infiltrates. Culture and cytology in BAL have a high specificity $(70-95 \%)$ but low sensitivity $(0-88 \%)$ for the diagnosis of IFD in neutropenic patients as assessed by histology [3]. Serum galactomannan has been suggested as a non-invasive marker for the diagnosis of IFD in neutropenic patients [4,5]. Conversely, a number of studies showed prominent false positive results [6,7]. The reported sensitivity of serum galactomannan ranges from 50 to $73 \%$ [8-10]. Herein, bronchoalveolar lavage galactomannan probably has a higher sensitivity than serum galactomannan [9]. Nevertheless, the specificity of serum galactomannan was $98 \%$ or higher in most collectives studied [11].

Currently, the gold-standard for diagnosis of invasive pulmonary aspergillosis remains the direct examination or culture of pulmonary tissue obtained by transbronchial or open lung biopsy [12]. Unfortunately, these procedures might be associated with considerable morbidity and mortality in this particular patient population. While transbronchial biopsies are considered safe in nonimmunosuppressed patients with a normal coagulation systems $[13,14]$ decreases in the platelet function or number are linked to a considerable increase in periinterventional parenchymal bleeding [15]. Surgical biopsy reliably allows detecting pulmonary IFD in a diagnostic and therapeutic approach $[16,17]$. However, both procedures require specialized, experienced physicians and institutions. Therefore, the development of a reliable, sensitive method to confirm the presence of invasive pulmonary aspergillosis would represent a desirable advance for the adequate treatment of patients at risk [12].

Molecular diagnostic methods for detection of fungal infection have been described in the immunosuppressed population. Khot et al. reported sensitivity, specificity, positive and negative predictive values of $77 \%, 88 \%, 50 \%$, 96\%, respectively, for a quantitative PCR in the bronchoalveolar lavage (BAL) of 81 patients with hematological malignancies or undergoing hematopoietic cell transplantation [18]. Tuon et al. reviewed 15 studies using PCR in BAL samples to detect invasive aspergillosis and described overall an sensitivity and specificity values of PCR-based techniques to be $79 \%$ and $94 \%$, respectivel [19]. Although major concerns related to the lack of external standardization, wide plethora of different methods (real-time, nested, etc.) and need for larger studies have been widely acknowledged, [19] the molecular diagnostic in the BAL seems to be a promising approach for the diagnosis of IFD. Hence, harmonization efforts are ongoing in order to help integrating PCR into the next revision of the EORTC classification [20].

In this study, we aimed to evaluate the diagnostic value of conventional nested PCR to detect aspergillus fumigatus, flavus, niger, glaucus, terreus and tomarrii in the bronchoalveolar fluids in a well-characterized, large population of immunosuppressed patients.

\section{Methods}

This is a prospective, investigator-initiated and -driven, observational, monocentric cohort study. Data of 191 immunocompromised patients undergoing flexible bronchoscopy over a two year period at the Clinic for Pulmonary Medicine, University Hospital Basel, a 784-bed tertiary care hospital located in Basel, Switzerland were analyzed. The primary goal of the study was to evaluate the diagnostic performance of conventional nested PCR to detect aspergillus fumigatus, flavus, niger, glaucus, terreus and tomarrii in the bronchoalveolar fluids for the diagnosis of invasive fungal disease in immunosuppressed patients.

Inclusion criteria were: a) age $\geq 18$, b) immunocompromised state as defined by hematologic or other malignancy treated by high-dose chemotherapy and/or stem cell transplantation; solid organ transplantation; AIDS; long-term corticosteroid therapy (i.e., $>=20 \mathrm{mg} / \mathrm{d}$ prednisone equivalent for $>=2$ months), current use of immunosuppressive, or cytotoxic medication for indications other than organ or stem cell transplantation; c) decision by the pulmonary consultant to perform bronchoscopy due to suspected pulmonary infection; d) informed consent by the patient to undergo flexible bronchoscopy and related data analysis. Exclusion criteria were pregnancy and inability to provide informed consent. The study was approved by the Basel Ethics Committee. All patients gave written informed consent.

\section{Definitions}

Suspected pulmonary infection was defined by the presence of respiratory symptoms, fever and/or new or progressive radiology findings, as judged by the attending physician.

Flexible bronchoscopy was performed with the patient under conscious sedation using hydrocodone and midazolam according to the British Thoracic Society guidelines [21]. BAL was performed by the three installations of $50 \mathrm{~mL}$ each of a pyrogen-free, sterile, $0.9 \% \mathrm{NaCL}$ solution over the working channel of the bronchoscope according to standard guidelines [22]. In patients with 
no or diffuse pulmonary infiltrates, BAL was performed either in the right middle lobe or the lingula. For patients with focal lung infiltrates, BAL was performed in the pulmonary segment corresponding to the radiologic abnormality. BAL fluid was recovered by suction. Besides BAL, the choice of further sampling techniques used during bronchoscopy, such as endo- or transbronchial biopsies or transbronchial needle aspiration, was at the pulmonologist's discretion.

The microbiological diagnostic workup included a search for Legionella pneumophila, Chlamydia pneumoniae, Mycoplasma pneumoniae, and respiratory viruses (i.e., herpes simplex virus, cytomegalovirus, respiratory syncytial virus, and adenovirus) by polymerase chain reaction, culture, or immunofluorescence. Appropriate stains and cultures for bacteria, mycobacteria, fungi, and Pneumocystis jiroveci were performed. Positive bacterial cultures were counted as the number of colony-forming units per milliliter, and identification and susceptibility tests were performed according to standard methods. Histologic lung biopsy specimens, recovered by transbronchial biopsy, endobronchial biopsy, video assisted thoracic surgery, and autopsy, were obtained according to the clinical setting. Cytologic analysis of BAL fluid was performed with hematoxylin-eosin staining. Cell differentiation in BAL fluid was reported as absolute numbers and as a percentage of the total cell count [22].

Severe neutropenia was defined as an absolute neutrophil count of $<0.5 \times 10^{9}$ cells/L.

Patients were examined, treated, and followed up according to the usual practice of the institution. Particularly, the decision to obtain tissue for histological examination was left at the discretion of the attending physician. Chest radiographs were performed in most cases, and CT scans were obtained, as indicated by the treating physicians, in $143(74.9 \%)$ patients. Clinical diagnoses were determined from physician notes, hospital discharge summaries, laboratory studies, radiologic examinations, and pathologic reports.

Invasive pulmonary aspergillosis was defined by the cytologic or histopathologic demonstration of the presence of Aspergillus or the isolation of Aspergillus in a respiratory specimen in the presence of a compatible clinical and radiographic pattern according to a consensus statement of the Invasive Fungal Infections Cooperative Group, European Organization for Research and Treatment of Cancer, and Mycosis Study Group of the National Institute of Allergy and Infectious Disease [23].

\section{Aspergillus conventional nested PCR}

Conventional nested PCR to detect aspergillus fumigatus, flavus, niger, glaucus, terreus and tomarrii was performed in $2.5 \mathrm{ml}$ leftovers of bronchoalveolar fluid. BAL material was centrifuged and DNA extracted from the pellet using EZ1 DNA Tissue Kit (QIAGEN AG, Hombrechtikon, Switzerland) as described by the manufacturer. The presence of adequate DNA was confirmed by amplifying the human beta-globin gene as previously described [24]. Previously described specific sequences of 5.8 sRNA and 18 sRNA of Aspergillus sp. were chosen as target sequences with slight modification [25]. The following primers were used for the detection of Aspergillus DNA: AspNest1 (5'-TCTTGGTTCCGGCATCGAT-3) and AspNest2 (5'TGACAAAGCCCCATACGCT-3') for the first round and AspNest3 (5'-GAAGAACGCAGCGAAATGC-3') and AspNest4 (5'-AACACACAAGCCGTGCTTGA-3') for the second round, respectively, leading to a final PCR product of $146 \mathrm{bp}$. The basic amplification reactions were done using a volume of $50 \mu$ l containing 100 to $500 \mathrm{ng}$ of DNA, $2.5 \mathrm{ml}$ of each primer (final concentration $3 \mathrm{mM}$ ), $25 \mu \mathrm{l}$ Master Mix Gold (Applied Biosystems, Paris, France) [26]. Amplification and detection were performed on the ABI 9800 Fast Thermal Cycler (Applied Biosystem) using for both primer sets, the same cycling conditions with an initial cycling step at $94^{\circ} \mathrm{C}$ for 10 minutes followed by $94^{\circ} \mathrm{C}, 55^{\circ} \mathrm{C}$ and $72^{\circ} \mathrm{C}$ for 30 seconds each ending at $4^{\circ} \mathrm{C}$. Ten microliters of each amplification product were analyzed by electrophoresis in an ethidium bromide-containing $2 \%$ agarose gel. In addition, PCR products were extracted from a low melting agarose gel and DNA sequencing was performed to confirm the appropriate DNA sequence. Stringent laboratory conditions and appropriate negative and positive controls were performed in each run.

\section{Statistical analysis}

Differences in dichotomous variables were evaluated using the Chi-square test or Fischer's exact test, as appropriate. Normally distributed parameters were analyzed using the Student's $t$-test for equality of means. All other continuously non-normally distributed parameters were evaluated using the non-parametric Mann-Whitney $U$ test or Kruskal-Wallis test, as appropriate.

The Statistical Package for Social Sciences (SSPS Inc, version 19 for Windows) program was used. All tests will be two-tailed; a $\mathrm{p}$ value of $<0.05$ was considered significant. Results will be expressed as mean (standard deviation) or median interquartile range unless otherwise stated.

\section{Results}

A total of 191 immunocompromised patients were included in the present study. Patient demographics are shown in Table 1. The mean age of the patient cohort was 50.5 years. The most common causes of immunosuppression were hematological malignancies (129 patients, $68 \%$ ), particularly acute myeloid leukemia (56 patients, $29 \%$ ) and malignant lymphoma (20 patients, 11\%). Median 
Table 1 Demographics of 191 immunosuppressed patients undergoing BAL for suspicion of Invasive fungal disease, classified according to the EORTC/NIAID

\begin{tabular}{|c|c|c|c|c|c|}
\hline Patient characteristics & All & Possible & Probable & Proven & No \\
\hline Patient number (\%) & 191(100) & $42(22)$ & $8(4.2)$ & $3(1.6)$ & 138(72.3) \\
\hline Age, yr & $50.5(19-80)$ & $44(22-80)$ & $49.5(24-60)$ & $42.67(29-70)$ & $52.4(19-79)$ \\
\hline Male gender (\%) & $116(60.7)$ & $28(66.7)$ & $4(50)$ & $3(100)$ & $81(58.7)$ \\
\hline \multicolumn{6}{|l|}{ Symptoms } \\
\hline Fever (\%) & $95(49.7)$ & 29(69) & $3(37)$ & $1(33.3)$ & $62(44.9)$ \\
\hline Cough (\%) & $97(50.8)$ & $22(52.4)$ & $4(50)$ & $1(33.3)$ & $70(50.7)$ \\
\hline Dyspnea (\%) & $75(39.3)$ & $15(35.7)$ & $4(50)$ & 0 & $56(40.6)$ \\
\hline Sputum (\%) & $40(20.9)$ & $10(23.8)$ & 0 & 0 & $30(21.7)$ \\
\hline Chills (\%) & 17(8.9) & $1(2.4)$ & $2(25)$ & 0 & 14(10.1) \\
\hline \multicolumn{6}{|l|}{ Chest radiograph/CT scan } \\
\hline Infiltrates (\%) & $105(55)$ & $24(57.1)$ & $6(75)$ & $2(66.7)$ & $73(52.9)$ \\
\hline Suspicion of fungi lesion (\%) & $53(27.7)$ & $17(40.5)$ & $4(50)$ & $3(100)$ & $29(21)$ \\
\hline \multicolumn{6}{|l|}{ Stem cell transplantation } \\
\hline Allogen (\%) & $48(25.1)$ & $11(26.2)$ & $4(100)$ & $3(100)$ & $30(21.7)$ \\
\hline Autolog (\%) & $12(6.3)$ & $6(14.3)$ & 0 & 0 & $6(4.3)$ \\
\hline \multicolumn{6}{|l|}{ Immunosuppressive therapy } \\
\hline Steroids (\%) & $67(35.1)$ & 13(31) & $2(25)$ & 0 & $52(37.7)$ \\
\hline Ciclosporine (\%) & $48(25.1)$ & $13(31)$ & $4(50)$ & $1(33.3)$ & $30(21.7)$ \\
\hline Mycophenolate (\%) & $28(14.7)$ & $4(9.5)$ & 0 & 0 & $24(17.4)$ \\
\hline Azathioprine (\%) & $9(4.7)$ & $2(4.8)$ & $1(12.5)$ & 0 & $6(5.3)$ \\
\hline Sirolimus (\%) & $10(5.2)$ & $2(4.8)$ & $1(12.5)$ & 0 & $7(5.1)$ \\
\hline Tacrolimus (\%) & $8(4.2)$ & 0 & 0 & 0 & $8(5.8)$ \\
\hline \multicolumn{6}{|c|}{ Antimicrobial therapy at bronchoscopy } \\
\hline Antibacterial (\%) & $163(85.3)$ & $39(92.9)$ & $8(100)$ & $3(100)$ & $113(81.3)$ \\
\hline Antiviral (\%) & $66(34.6)$ & $13(31)$ & $3(37.5)$ & $2(66.7)$ & $48(34.8)$ \\
\hline Antifungal (\%) & $111(58.1)$ & $32(76.2)$ & $7(87.5)$ & $3(100)$ & $69(50)$ \\
\hline \multicolumn{6}{|l|}{ Disease } \\
\hline Hematologic disorders (\%) & $129(67.5)$ & $33(78.6)$ & $8(100)$ & $3(100)$ & $85(61.6)$ \\
\hline Solid organ transplants (\%) & $26(13.6)$ & $4(9.5)$ & 0 & 0 & $22(15.9)$ \\
\hline AIDS (\%) & $12(6.3)$ & 0 & 0 & 0 & $12((8.7)$ \\
\hline Autoimmune disorders (\%) & $24(12.6)$ & $5(11.9)$ & 0 & 0 & 19(13.8) \\
\hline \multicolumn{6}{|l|}{ Microbiology } \\
\hline Aspergillus culture BAL (\%) & $8(4.2)$ & $2(4.8)$ & $2(25)$ & $1(33.3)$ & $3(2.2)$ \\
\hline Bacteriology BAL (\%) & $28(14.7)$ & $3(7.1)$ & $1(12.5)$ & 0 & $24(17.4)$ \\
\hline Positive nPCR BAL (\%) & $55(28.8)$ & $10(23.8)$ & $4(50)$ & 0 & $41(29.7)$ \\
\hline Galactamannan in blood, ng/ml & $0.226(0.1-3)$ & $0.171(0.1-0.5)$ & $0.488(0.1-1.3)$ & $1.1(0.1-3)$ & $0.178(0.1-1.3)$ \\
\hline $\mathrm{CRP}(\mathrm{mg} / \mathrm{L})$ & $76.4(0-410)$ & $84.8(0.9-296)$ & $71.8(2.9-240)$ & $61.6(6.8-116)$ & $74(0-410)$ \\
\hline Leukocytes (x10²/L) & 7.8 & 4.8 & 2.0 & 2.1 & 9.2 \\
\hline BAL cells $\left(\times 10^{6 / L}\right)$ & 313.8 & 183.6 & 159.4 & 678.3 & 351.6 \\
\hline macrophages (in\%) & 69.1 & 71.0 & 82.4 & 60.5 & 68 \\
\hline lymphocytes (in\%) & 15.7 & 15.3 & 11.8 & 4.0 & 16.2 \\
\hline neutrophiles (in\%) & 16.4 & 9.4 & 6.7 & 35.5 & 18.5 \\
\hline eosinophiles (in\%) & 0.9 & 0.8 & 0.8 & 0.0 & 1 \\
\hline
\end{tabular}

Abbreviations: $\mathrm{BAL}=$ Bronchoalveolar lavage. 
leukocyte counts and CRP were similar in all patient groups $(\mathrm{p}=\mathrm{ns})$. Overall, $60(31 \%)$ of the patients underwent stem cell transplantation. Mean duration of hospitalization before bronchoscopy was $11.1( \pm 18.6)$ days. The vast majority of patients required bronchoscopy due to fever and cough. Fifty-five percent presented infiltrates in the chest-x-ray, where up only $28 \%$ where considered to be suspected of IFD by the radiologists. A total of $85 \%$ of the patients were on antibiotics, $58 \%$ on antifungal and $35 \%$ on antiviral therapy at the time of bronchoscopy.

In addition to bronchoalveolar lavage, 15 (7.9\%) transbronchial biopsies, 11 (5.8\%) endobronchial biopsies and 3 (1.6\%) TBNA from the parenchyma have been performed during bronchoscopy. There were no major complications of the procedure. Cytological analysis of BAL revealed a mean of $313 \times 10^{6}$ cells, hereby $69 \%$ macrophages, $16 \%$ neutrophiles, $16 \%$ lymphocytes, and $1 \%$ eosinophiles. There was no difference in the differential cell counts among patients with proven, probable and possible IFD.

Histological confirmation of the diagnosis was achieved in 35 patients. Eight (4.2\%) patients were submitted to open lung biopsy. Out of 37 deaths observed in the study, a total of 24 autopsies were performed. In 2 cases without autopsy, further tissue sections were previously obtained for examination (transbronchial biopsy, open lung biopsy, one case each). Thus, histology was available in $57(29.8 \%)$ cases and in $26(70.3 \%)$ of the deceased patients.

\section{Diagnostic performance of conventional nested Aspergillus PCR according to the EORTC/NIAID classification}

According to the EORTC/NIAID classification, "proven", "probable", "possible" and "no" IFD was present in 3 (2\%), 8 (4\%), $42(22 \%)$ and $138(72 \%)$ of the cases, respectively. Therefore, there were 53 patients with potential IFD. Conventional nested PCR in the BAL was positive in 55 cases (29\%). From these, $0 / 3(0 \%)$ in proven, $4 / 8(50 \%)$ in probable, $10 / 42(24 \%)$ in possible and $41 / 138(30 \%)$ in no IFD. Sensitivity, specificity, positive and negative predictive value of conventional nested PCR according to the radiological and clinical suspicion of IFD is presented in Table 2.

In $53(28 \%)$ cases there was a strong clinical suspicion of IFD in the chest-x-ray and/or chest-CT irrespective of the EORTC/NIAID classification. However, from those, only 15 (28\%) had a positive conventional nested PCR.

Conventional nested PCR in the BAL was positive in $36 / 129$ patients with hematologic disorders, $8 / 26$ cases of solid organ transplantation, 2/12 patients with AIDS and $9 / 24$ with autoimmune disorders. Thus, the underlying cause of immunsuppression did not significantly influence PCR results in this study $(p=0.605)$ There was no difference in PCR positivity among allogen (13/48), autolog (5/12) and no (37/131) stem-cell transplant recipients either $(\mathrm{p}=0.589)$.

A total of $111(58 \%)$ of the patients were on antifungal therapy at the time of bronchoscopy. Thereby, anti-fungal therapy was administer to $10 / 11$ (90.9\%) of the patients with proven or probable IFD and 32/42 (76.2\%) patients with possible IFD, respectively. Results of serum galactomannan were assessed in 105 patients (55\%). In 4 cases, galactomannan was considered positive $(>0.5 \mathrm{ng} / \mathrm{ml})$. From those, $2(50 \%)$ had a positive PCR results. Galactomannan blood levels were similar across all EORTC/NIAID groups $(\mathrm{p}=0.123)$.

\section{Discussion}

In this study, we report the diagnostic performance of conventional nested aspergillus PCR in the BAL fluid in a well-characterized cohort of 191 immunosuppressed patients. To our knowledge, this is the largest cohort of IFD cases being prospectively analyzed by aspergillus PCR in the BAL. Remarkably and in contrast to previous data, our results fail to support the clinical applicability of aspergillus PCR in the BAL in the immunosuppressed population, mainly due to the lack of sensitivity and specificity of the method.

Our results are in contrast to some but not all previously published studies. While several authors [27-31] suggested the sensitivity of aspergillus PCR in the BAL to range between $80 \%$ and $100 \%$, other authors described much poorer results. For instance, Skladny et al. reports a sensitivity of $43 \%$ for proven and $33 \%$ for probable IFD using BAL PCR [19,32]. Remarkably, false negative results in proven IFD have been described commonly. Buchheidt et al. detected negative PCR results in the BAL of two out of three patients with positive histological findings for invasive Aspergillosis [33] and Khot et al. reported a negative PCR result from one patient with a positive biopsy [18].

The low sensitivity of the assay in our study might have several reasons. Firstly, we have additionally computed the diagnostic performance of the assay by incorporating the group of "possible" IFD as potentially having IFD. As more cases not "formally" suffering from IFD are included as diseased, there is a decrease in the pretest-probability, thus further reducing the sensitivity of the test from $36 \%$ to $26 \%$, as depicted in Table 2 . Secondly, previous studies selected patients by definite radiographic findings or pneumonia, thus improving the pre-test probability of the assay [18,29]. Thirdly, the majority of our patient population (almost 60\%) was on chronic anti-fungal therapy at the time of bronchoscopy, which might have decreased the number of organisms present in the pulmonary parenchyma and consequently in the BAL fluid, thus impairing identification by BAL 
Table 2 Diagnostic performance of conventional nested Aspergillus PCR $^{\mathrm{a}}$

\begin{tabular}{|c|c|c|c|c|}
\hline & Sensitivity & Specificity & $P P V$ & NPV \\
\hline \multicolumn{5}{|l|}{ As compared to EORTC/NIAID } \\
\hline Proven & $0 \%$ & $71 \%$ & $0 \%$ & $98 \%$ \\
\hline Proven \& Probable & $36 \%$ & $72 \%$ & $7 \%$ & $95 \%$ \\
\hline Proven \& Probable \& Possible & $26 \%$ & $70 \%$ & $26 \%$ & $71 \%$ \\
\hline \multicolumn{5}{|l|}{$\begin{array}{l}\text { As compared to clinical } \\
\text { judgment }\end{array}$} \\
\hline Receiving antifungal therapy & $30 \%$ & $73 \%$ & $60 \%$ & $43 \%$ \\
\hline $\begin{array}{l}\text { Suspicion of IFD on radiologic } \\
\text { studies }\end{array}$ & $28 \%$ & $71 \%$ & $27 \%$ & $72 \%$ \\
\hline
\end{tabular}

$\mathrm{IFD}=$ invasive fungal disease.

PCR [34,35]. Importantly, data on previous fungal therapy are missing in most previous reports $[25,29,30,36]$. As compared to older studies, it is plausible that recently introduced, highly potent anti-fungal therapy such as voriconazol and new prophylactic treatment schemata's reduce fungal load to undetectable amounts in the extra vascular compartments. Fourthly, as only selected aspergillus primers have been applied, detection of other fungal microorganisms was not possible using the current assay. Although most IFD cases are related to aspergillus infection, other fungi such as mucormycosis or rhizophus with a similar or identical clinical presentation would have been missed with the selected primers. Fifthly, it is tempting to hypothesize that fungal microorganisms are mainly present in the intravascular space, thus precluding identification in the alveolar space. And finally, we cannot exclude a technical failure of the methods, although the consistency of the findings and the broad experience of the investigators with molecular techniques make this possibility unlikely [37-40].

In the current study, only 3 patients full field the criteria of "proven" IFD according to the EORTC/NIAID classification. Nevertheless, all presented a false-negative result showing a negative PCR for Aspergillus in BAL. In the first case, the patient had been on antifungal therapy over 6 month at the time of bronchoscopy. Surprisingly, with the exception of the positive histology obtained by video-assisted thoracoscopic surgery, clinical EORTC/ NIAID classification was negative due to the absence of neutropenia, fever, graft vs. host disease and current steroid therapy, e.g. "no" IFD. In the second case, the patient was on cyclosporine, had a suspicion of fungal infection due to the presence of a coin lesion on thoracic CT-scan as well as a positive aspergillus culture in the BAL, thus fulfilling the "probable" clinical criteria for IFD. The third patient with a proven biopsy had a new "fungi" suspect infiltrate in the CT scan, but low clinical signs ("possible") for IFD according to the EORTC/ NIAID classification. This exemplifies the low agreement between the EORTC/NIAID classification, histological findings and the clinical presentation in IFD. In all three cases, the suspicion of fungal disease raised by the radiologist lead to the initiation of antifungal medication.

While our results suggest an unexpected low sensitivity of the aspergillus PCR in the BAL, the specificity of the test is in line with previously reported data. Historical controls have shown specificities ranging between $84 \%$ and $100 \%[18,29,30]$. This can be explained by the small number of proven invasive aspergillosis.

Our study has a few limitations. The limited number of "proven" and "probable" IFD cases hampers robust inferences on the diagnostic performance of the any test due the low prevalence of the disease (=low pre-test probability). Moreover, the lack of a reliable diagnostic gold-standard for IFD in the absence of histological samples and the heterogeneous clinical presentation of the disease limit the diagnostic certainty in the majority of cases. And finally, despite all efforts, we cannot definitively exclude the possibility of a technical failure in the assay procedure.

\section{Conclusions}

In summary, our results suggest a limited clinical applicability of aspergillus PCR in the BAL for the detection of invasive fungal disease (specifically invasive aspergillosis) in a population of immunosuppressed patients.

\section{Abbreviations \\ AIDS: Auto Immune Deficiency Syndrome; BAL: Bronchoalveolar Lavage; CT: Computer Tomography; DNA: Desoxyribonucleinacid; EORTC/ NIAID: European Organization for Research and Treatment of Cancer and National Institute of Allergy and Infectious Diseases; IFD: Invasive Fungal Disease; nPCR: Conventional nested Polymerase Chain Reaction.}

\section{Competing interests}

The authors declare that they have no competing interests.

\section{Authors' contributions}

MB, MT, DS conceived and designed the study, revised the patients' charts, analyzed the data, performed statistical analysis and drafted the manuscript. GC carried out the assays and drafted the manuscript. JH, LJ, PG participated in the design and coordination of the study and helped to draft the manuscript. All authors read and approved the final manuscript.

\section{Acknowledgements}

We thank Anja Meyer RN, Werner Strobel MD and the endoscopy department (Clinic of Pulmonary Medicine and Respiratory Cell Research) for their most valuable help during the study.

\section{Author details}

${ }^{1}$ Clinic of Pulmonary Medicine and Respiratory Cell Research, University Hospital Basel, Basel, Switzerland. ${ }^{2}$ Clinic for Hematology, University Hospital Basel, Basel, Switzerland. ${ }^{3}$ Department of Microbiology, Kanton Hospital Liestal, Liestal, Switzerland.

Received: 26 March 2012 Accepted: 24 September 2012

Published: 2 October 2012

\section{References}

1. Herbrecht R, Denning DW, Patterson TF, Bennett JE, Greene RE, Oestmann JW, Kern WW, Marr KA, Ribaud P, Lortholary O, et al: Voriconazole versus 
amphotericin B for primary therapy of invasive aspergillosis. N Engl J Med 2002, 347(6):408-415.

2. Kim A, Nicolau DP, Kuti JL: Hospital costs and outcomes among intravenous antifungal therapies for patients with invasive aspergillosis in the United States. Mycoses 2011, 54(5):e301-12. doi:10.1111/j.14390507.2010.01903.x. Epub 2010 Jun 14.

3. Reichenberger $F$, Habicht J, Matt $P$, Frei $R$, Soler M, Bolliger $C T$, Dalquen $P$, Gratwohl A, Tamm M: Diagnostic yield of bronchoscopy in histologically proven invasive pulmonary aspergillosis. Bone Marrow Transplant 1999, 24(11):1195-1199.

4. Weisser M, Rausch C, Droll A, Simcock M, Sendi P, Steffen I, Buitrago C, Sonnet S, Gratwohl A, Passweg J, et al: Galactomannan does not precede major signs on a pulmonary computerized tomographic scan suggestive of invasive aspergillosis in patients with hematological malignancies. Clin Infect Dis 2005, 41(8):1143-1149.

5. Danpornprasert P, Foongladda S, Tscheikuna J: Impact of bronchoalveolar lavage galactomannan on the outcome of patients at risk for invasive pulmonary aspergillosis. J Med Assoc Thai 2010, 93(Suppl 1):S86-93.

6. Clancy CJ, Jaber RA, Leather $\mathrm{HL}$, Wingard JR, Staley B, Wheat LJ, Cline CL, Rand $\mathrm{KH}$, Schain D, Baz M, et al: Bronchoalveolar lavage galactomannan in diagnosis of invasive pulmonary aspergillosis among solid-organ transplant recipients. J Clin Microbiol 2007, 45(6):1759-1765.

7. Verweij PE, Latge JP, Rijs AJMM, Melchers WJG, Depauw BE, Hoogkampkorstanje JAA, Meis JFGM: Comparison of Antigen-Detection and Pcr Assay Using Bronchoalveolar Lavage Fluid for Diagnosing Invasive Pulmonary Aspergillosis in Patients Receiving Treatment for Hematological Malignancies. J Clin Microbiol 1995, 33(12):3150-3153.

8. Pazos C, del Palacio A: Early diagnosis of invasive aspergillosis in neutropenic patients with bi-weekly serial screening of circulating galactomannan by Platelia Aspergillus. Rev Iberoam Micol 2003, 20(3):99-102.

9. Luong ML, Filion C, Labbe AC, Roy J, Pepin J, Cadrin-Tourigny J, Carignan S, Sheppard DC, Laverdiere M: Clinical utility and prognostic value of bronchoalveolar lavage galactomannan in patients with hematologic malignancies. Diagn Microbiol Infect Dis 2010, 68(2):132-139.

10. Reinwald M, Spiess B, Heinz WJ, Vehreschild JJ, Lass-Florl C, Kiehl M, Schultheis B, Krause SW, Wolf HH, Bertz H, et al: Diagnosing pulmonary aspergillosis in patients with hematological malignancies: a multicenter prospective evaluation of an Aspergillus PCR assay and a galactomannan ELISA in bronchoalveolar lavage samples. Eur I Haematol 2012, 89(2):120-7. doi:10.1111/j.1600-0609.2012.01806.x. Epub 2012 Jun 22.

11. Moragues MD, Amutio E, Garcia-Ruiz JC, Ponton J: Usefulness of galactomannan detection in the diagnosis and follow-up of hematological patients with invasive aspergillosis. Rev Iberoam Micol 2003, 20(3):103-110.

12. Ascioglu S, Rex JH, de Pauw B, Bennett JE, Bille J, Crokaert F, Denning DW, Donnelly JP, Edwards JE, Erjavec Z, et al: Defining opportunistic invasive fungal infections in immunocompromised patients with cancer and hematopoietic stem cell transplants: an international consensus. Clin Infect Dis 2002, 34(1):7-14.

13. Hernandez Blasco L, Sanchez Hernandez IM, Villena Garrido V, de Miguel Poch E, Nunez Delgado M, Alfaro Abreu J: Safety of the transbronchial biopsy in outpatients. Chest 1991, 99(3):562-565.

14. Ahmad M, Livingston DR, Golish JA, Mehta AC, Wiedemann HP: The safety of outpatient transbronchial biopsy. Chest 1986, 90(3):403-405.

15. Ernst A, Eberhardt R, Wahidi M, Becker HD, Herth FJ: Effect of routine clopidogrel use on bleeding complications after transbronchial biopsy in humans. Chest 2006, 129(3):734-737.

16. Reichenberger F, Habicht J, Kaim A, Dalquen P, Bernet F, Schlapfer R, Stulz P, Perruchoud AP, Tichelli A, Gratwohl A, et al: Lung resection for invasive pulmonary aspergillosis in neutropenic patients with hematologic diseases. Am J Respir Crit Care Med 1998, 158(3):885-890.

17. Nebiker C, Lardinois D, Junker L, Gambazzi F, Matt P, Habicht J, Halter J, Heim D, Stern M, Buser A, et al: Lung resection in hematologic patients with pulmoary invasive fungal disease. Chest 2012, in press.

18. Khot PD, Ko DL, Hackman RC, Fredricks DN: Development and optimization of quantitative PCR for the diagnosis of invasive aspergillosis with bronchoalveolar lavage fluid. BMC Infect Dis 2008, 8:73.

19. Tuon FF: A systematic literature review on the diagnosis of invasive aspergillosis using polymerase chain reaction (PCR) from bronchoalveolar lavage clinical samples. Rev Iberoam Micol 2007 24(2):89-94.
20. White PL, Perry MD, Loeffler J, Melchers W, Klingspor L, Bretagne $S$, McCulloch E, Cuenca-Estrella M, Finnstrom N, Donnelly JP, et al: Critical stages of extracting DNA from Aspergillus fumigatus in whole-blood specimens. J Clin Microbiol 2010, 48(10):3753-3755.

21. Stolz D, Chhajed PN, Leuppi JD, Brutsche M, Pflimlin E, Tamm M: Cough suppression during flexible bronchoscopy using combined sedation with midazolam and hydrocodone: a randomised, double blind, placebo controlled trial. Thorax 2004, 59(9):773-776.

22. Stolz D, Stulz A, Muller B, Gratwohl A, Tamm M: BAL neutrophils, serum procalcitonin, and C-reactive protein to predict bacterial infection in the immunocompromised host. Chest 2007, 132(2):504-514.

23. De Pauw B, Walsh TJ, Donnelly JP, Stevens DA, Edwards JE, Calandra T, Pappas PG, Maertens J, Lortholary O, Kauffman CA, et al: Revised definitions of invasive fungal disease from the European Organization for Research and Treatment of Cancer/Invasive Fungal Infections Cooperative Group and the National Institute of Allergy and Infectious Diseases Mycoses Study Group (EORTC/MSG) Consensus Group. Clin Infect Dis 2008, 46(12):1813-1821.

24. Cathomas G, Stalder A, McGandy CE, Mihatsch MJ: Distribution of human herpesvirus 8 DNA in tumorous and nontumorous tissue of patients with acquired immunodeficiency syndrome with and without Kaposi's sarcoma. Modern pathology: an official journal of the United States and Canadian Academy of Pathology, Inc 1998, 11(5):415-420.

25. Pham AS, Tarrand JJ, May GS, Lee MS, Kontoyiannis DP, Han XY: Diagnosis of invasive mold infection by real-time quantitative PCR. Am J Clin Pathol 2003, 119(1):38-44.

26. Zsikla V, Hailemariam S, Baumann M, Mund MT, Schaub N, Meier R, Cathomas G: Increased rate of Helicobacter pylori infection detected by PCR in biopsies with chronic gastritis. Am J Surg Pathol 2006, 30(2):242-248.

27. Luong ML, Clancy CJ, Vadnerkar A, Kwak EJ, Silveira FP, Wissel MC, Grantham KJ, Shields RK, Crespo M, Pilewski J, et al: Comparison of an Aspergillus real-time polymerase chain reaction assay with galactomannan testing of bronchoalvelolar lavage fluid for the diagnosis of invasive pulmonary aspergillosis in lung transplant recipients. Clinical infectious diseases: an official publication of the Infectious Diseases Society of America 2011, 52(10):1218-1226.

28. Shahid M, Malik A, Bhargava R: Bronchogenic carcinoma and secondary aspergillosis-common yet unexplored: evaluation of the role of bronchoalveolar lavage-polymerase chain reaction and some nonvalidated serologic methods to establish early diagnosis. Cancer 2008, 113(3):547-558.

29. Raad I, Hanna H, Huaringa A, Sumoza D, Hachem R, Albitar M: Diagnosis of invasive pulmonary aspergillosis using polymerase chain reaction-based detection of aspergillus in BAL. Chest 2002, 121(4):1171-1176.

30. Buchheidt D, Baust C, Skladny H, Ritter J, Suedhoff T, Baldus M, Seifarth W, Leib-Moesch C, Hehlmann R: Detection of Aspergillus species in blood and bronchoalveolar lavage samples from immunocompromised patients by means of 2-step polymerase chain reaction: clinical results. Clin Infect Dis 2001, 33(4):428-435.

31. Hayette MP, Vaira D, Susin F, Boland P, Christiaens G, Melin P, De Mol P: Detection of Aspergillus species DNA by PCR in bronchoalveolar lavage fluid. J Clin Microbiol 2001, 39(6):2338-2340.

32. Skladny H, Buchheidt D, Baust C, Krieg-Schneider F, Seifarth W, Leib-Mosch C, Hehlmann R: Specific detection of Aspergillus species in blood and bronchoalveolar lavage samples of immunocompromised patients by two-step PCR. J Clin Microbiol 1999, 37(12):3865-3871.

33. Buchheidt D, Baust C, Skladny H, Baldus M, Brauninger S, Hehlmann R: Clinical evaluation of a polymerase chain reaction assay to detect Aspergillus species in bronchoalveolar lavage samples of neutropenic patients. Br J Haematol 2002, 116(4):803-811.

34. Reinwald M, Hummel M, Kovalevskaya E, Spiess B, Heinz WJ, Vehreschild JJ, Schultheis B, Krause SW, Claus B, Suedhoff T, et al: Therapy with antifungals decreases the diagnostic performance of PCR for diagnosing invasive aspergillosis in bronchoalveolar lavage samples of patients with haematological malignancies. J Antimicrob Chemother 2012, 67(9):2260-7. Epub 2012 Jun 27

35. Marr KA, Laverdiere M, Gugel A, Leisenring W: Antifungal therapy decreases sensitivity of the Aspergillus galactomannan enzyme immunoassay. Clin Infect Dis 2005, 40(12):1762-1769.

36. Rantakokko-Jalava K, Laaksonen S, Issakainen J, Vauras J, Nikoskelainen J, Viljanen MK, Salonen J: Semiquantitative detection by real-time PCR of 
Aspergillus fumigatus in bronchoalveolar lavage fluids and tissue biopsy specimens from patients with invasive aspergillosis. J Clin Microbiol 2003, 41(9):4304-4311.

37. Cathomas G: Molecular diagnostic in infectious disease pathology: an update. Ann Pathol 2009, 29(Spec No 1):S19-21.

38. Regamey N, Tamm M, Wernli M, Witschi A, Thiel G, Cathomas G, Erb P. Transmission of human herpesvirus 8 infection from renal-transplant donors to recipients. N Engl J Med 1998, 339(19):1358-1363.

39. Hofman V, Dhouibi A, Butori C, Padovani B, Gari-Toussaint M, Garcia-Hermoso D, Baumann M, Venissac N, Cathomas G, Hofman P: Usefulness of molecular biology performed with formaldehyde-fixed paraffin embedded tissue for the diagnosis of combined pulmonary invasive mucormycosis and aspergillosis in an immunocompromised patient. Diagn Pathol 2010, 5:1.

40. Tamm M, Traenkle P, Grilli B, Soler M, Bolliger CT, Dalquen P, Cathomas G: Pulmonary cytomegalovirus infection in immunocompromised patients. Chest 2001, 119(3):838-843.

doi:10.1186/1471-2334-12-237

Cite this article as: Buess et al: Aspergillus-PCR in bronchoalveolar lavage for detection of invasive pulmonary aspergillosis in

immunocompromised patients. BMC Infectious Diseases 2012 12:237.

\section{Submit your next manuscript to BioMed Central and take full advantage of:}

- Convenient online submission

- Thorough peer review

- No space constraints or color figure charges

- Immediate publication on acceptance

- Inclusion in PubMed, CAS, Scopus and Google Scholar

- Research which is freely available for redistribution 